\title{
De escribanos de número a alcaldes mediante la violencia (1577-1597): el «cuento de los asientos» del Quijote y su verosimilitud en «La Mancha» del siglo XVI (Don Quijote, II, 31) From Public Notaries to Mayors through Violence (1577-1597): Verisimilitude in Don Quixote's «Tale of the Seats» inside «The Manxa» of the Sixteenth Century (Don Quixote, II, 31)
}

\section{Francisco Javier Escudero Buendía}

https://orcid.org/0000-0001-6990-3011

Técnico de Archivos

Junta de Comunidades de Castilla-La Mancha

ESPAÑA

fescuderob@jccm.es

[Hipogrifo, (issn: 2328-1308), 9.2, 2021, pp. 103-125]

Recibido: 25-02-2021/ Aceptado: 22-07-2021

DOI: http://dx.doi.org/10.13035/H.2021.09.02.09

Resumen. Se propone que este episodio se asienta sobre fuentes folklóricas e históricas, ya que partiendo de un argumento base que sería una anécdota oral cortesana recogida en El Pasajero de Cristóbal Suárez de Figueroa (1617) sobre la que Cervantes pudo disponer informaciones y personajes históricos de su ámbito autobiográfico y toledano, idea que sigue y también enmienda hipótesis anteriores como las de Rodríguez Marín (1913) y Marañón (1945). 
Palabras clave. Miguel de Cervantes; don Quijote de la Mancha; Novelas ejemplares; fuentes documentales; cuentos folklóricos; personajes históricos; verosimilitud.

Abstract. It is proposed that this episode is based on folkloric and historical sources, since starting from a basic argument that it would be a courtesan oral anecdote collected in The passenger by Cristóbal Suárez de Figueroa (1617) on which Cervantes was able to provide information and historical characters around autobiographical experiences from Toledo, idea that follows although also amends previous hypotheses such as those of Rodríguez Marín (1913) and Marañón (1945).

Keywords. Miguel de Cervantes; don Quixote of The Manxa; Exemplary Novels; Source documents; Folkloric tales; Historical figures; Verisimilitude.

«Si sus mercedes me dan licencia, les contaré un cuento que pasó en mi pueblo acerca desto de los asientos» (Quijote, II, 31)

\section{INTRODUCCIÓN. EL «CUENTO DE LOS ASIENTOS», DESDE EL PUNTO DE VISTA HISTORIOGRÁFICO UNA NARRACIÓN INTERPOLADA MÁS}

La complejidad del relato quijotesco en todos sus puntos es ya legendaria, y en el caso que nos ocupa, el que podríamos llamar «cuento de los asientos», no será diferente; en este episodio Sancho Panza, más allá de contar una historia, se eterniza con ínfimos detalles que no vienen al $\mathrm{caso}^{7}$, digresiones, interpelaciones a su amo y al religioso presente, sin llegar nunca a concretar un final plausible y que hace que aumente el disfrute de los Duques proporcionalmente a todo lo que supone de vergüenza para el personaje de don Quijote (Quijote, II, 31).

Desde nuestro punto de vista, presenciamos una narración con todos los caracteres de una historia interpolada más, incluso podríamos encontrarnos como veremos con la estructura y elementos básicos de una novela ejemplar en cuanto al análisis de sus fuentes históricas y folklóricas, que por ser breve no implica que carezca de ellos: estructura en forma transversal donde se disponen en diferentes niveles personajes y linajes con nombres ligeramente cambiados, peripecias y biografías que se insinúan y detalles que nos dirigen a la autobiografía del autor como sus menciones a escritores, Toledo y berbería.

Frente a casos similares que en la primera parte del Quijote han merecido numerosos y complejos estudios hasta completar una corriente dentro del cervantismo - historias interpoladas de carácter pastoril, italianizante, cautivero y frontera, sentimental ${ }^{2}$, incluso otras como la inacabada de los galeotes y Jerónimo de Pasamonte ${ }^{3}$, en el caso que nos ocupa, no ha sido así.

\footnotetext{
1. Da Costa Vieira, 2015, p. 390.

2. Riley, 1989.

3. Baquero Escudero, 1991, pp. 417-424; y 2013, pp. 70-71
} 
De hecho existe abundante bibliografía sobre cuentos mucho más breves que este de «los asientos» y podemos traer a colación el llamado «de nunca acabar», conocido también como el de la «Torralba y Lope Ruiz» (Quijote, I, 20) del que se han destacado sus orígenes orales, folklóricos, medievales y se han aportado hasta diferentes versiones anteriores que pudieron influir en la definitiva cervantina ${ }^{4}$.

Para abordar entonces uno de los escasos análisis que se han realizado sobre este episodio en el tema de sus fuentes, nos vamos a centrar principalmente en la interpretación también apresurada de cuatro momentos de la historia que se precipitan y atropellan entre sí, con un relato que se construye como una narración de pensamientos aparentemente $-y$ solo aparentemente- inconexos del personaje de Sancho Panza:

-Fuentes folklóricas del argumento base: El Pasajero de Cristóbal Suárez de Figueroa (1617).

-Personaje principal: un hidalgo Ilamado Álamo procedente de Medina del Campo.

- Personaje secundario: un caballero denominado Alonso de Marañón.

-Entorno histórico: una pendencia en La Mancha como detalle accesorio.

\section{UN ACERCAMIENTO A LAS FUENTES FOLKLÓRICAS DEL ARGUMENTO PRINCIPAL}

En un primer momento para el tema de las fuentes prácticamente tenemos que retrotraernos a los tiempos de la teoría de los modelos vivos y por tanto a bibliografía de principios del siglo $X x^{5}$, en concreto a Francisco Rodríguez Marín, citado posteriormente por Vicente Gaos. Según estos autores, la historia principal tendría su origen en algún relato o historia oral que corría apócrifo por los mentideros de Castilla y ofrecen un ejemplo sacado de la edición que realizó el citado de El Pasajero de Cristóbal Suárez de Figueroa (1913)6, obra que se editó originalmente solo dos años después de la muerte de Cervantes (1617)

Según Jonathan Brandbury y Blandine Daguerre, esta novela entraría dentro de la categoría de «misceláneas», es decir un conjunto de relatos interpolados divididos en categorías: retratos de personajes arquetípicos de la época, cuentos populares, chistes, narraciones con raíz historicista, historia propia de los narradores $^{8}$. Permítannos la licencia de admitir que las similitudes son tales que también han sido destacadas recientemente por el último editor de este mismo opúsculo $(2018)^{9}$, y a nosotros no nos cabe duda de que al igual que Figueroa, Cervantes pudo perfectamente haberla escuchado en el mismo entorno, que no leído pues-

4. Díaz-Mas, 2005; Martín Morán, 1999.

5. García López, 1999, p. 189.

6. Suárez de Figueroa, El Pasajero, ed. Francisco Rodríguez Marín.

7. Bradbury, 2016.

8. Daguerre, 2020, p. 75.

9. «La anécdota que aportará Figueroa recuerda la del hidalgo y el labrador que relata Sancho Panza en dQ2-XXX|». Suárez de Figueroa, 2018, p. 647. 
to que el texto de este es posterior, dado que tenía tendencia a incluir menciones folklóricas de este tipo que luego pasaron a ser reflejadas por escrito en diversas colecciones de sucesos. Así lo han destacado Isabel Lozano-Renieblas ${ }^{10}$ y Agustín Redondo ${ }^{11}$ para el Persiles como, por poner un ejemplo muy conocido, la de La Camacha de El coloquio de los perros (1613) ${ }^{12}$ :

Ofreceseme con un Duque de Medina Sidonia. Púsose inaduertidamente el hombre a la mano derecha de aquel príncipe, y habiendo andado algunos pasos, reconocido su yerro, dijo con grande sumisión: «Perdone vuestra Excelencia el no haber estado en lo hecho». Y tras esto quiso mudar lugar. Respondió el Duque: «Bien vais, que yo en cualquier parte soy el mismo». Y mandó pasase adelante como iba ${ }^{13}$

En el cuento original el protagonista es el duque de Medina Sidonia, no el Álamo cervantino que será después, tampoco hay asientos, sino la posición a la diestra en un desfile; sin embargo la reacción del prócer fue sorprendente para la época, la misma que en el «cuento de los asientos», y mostrando humildad se impuso una realidad palmaria: independientemente del puesto que ocupe seguiré siendo la misma persona.

Si seguimos leyendo un poco más adelante la novela de Cristóbal Suárez de Figueroa, podríamos decir que la moraleja final de su propio cuento y la de toda la obra, porque es la última historia que se nos cuenta, es todavía más cercana al relato de Sancho y tan gráfica, porque aquí sí se citan expresamente los famosos asientos, que no podemos dejar de pensar que era también parte del mensaje que nos quería transmitir Cervantes al incluir este relato interpolado en el Quijote:

Impertinencia es, dando algún lugar o asiento más preeminente, hacerse mucho de rogar para acetarle, pues la humildad puede abonar la intención con que se admite, que es de no porfiar. Tomarle de su mano es error grandísimo, con que descubre el tal ser ambicioso de honra, vano y ligero ${ }^{14}$.

Hoy día la cuestión de la posición en una mesa o un desfile nos podría parecer un tema baladí, pero en la época la precedencia de un puesto sobre otro por ejemplo entre embajadores de diferentes países, entre autoridades civiles y eclesiásticas o entre un linaje y otro saltándose la tradición o la pretendida preponderancia de unos sobre otros, podría ser perfectamente asunto diplomático y llegar a oídos del rey o del papa correspondiente; sin ser exhaustivo, es bien conocida la prohibición de Felipe II de que su embajador español participe en actos públicos una vez que el

10. Lozano-Renieblas, 2014, p. 75

11. Redondo, 2012, p. 119.

12. Ramírez de las Casas Deza, 1836, pp. 24-29.

13. Cervantes, El ingenioso hidalgo don Quijote de la Mancha, ed. Rodríguez Marín, p. 250.

14. Suárez de Figueroa, 2018, p. 647. 
papa Pío IV reconoce la precedencia del representante francés $(1564)^{15}$, o la orden papal de retirada de la silla del Arzobispo de Génova una vez que el dux la había desplazado a la nave de la epístola, mediando hasta el propio rey Luis XIV (1640) ${ }^{16}$.

Si esto era así en las más altas instancias, al nivel local como lo rebaja el relato sanchesco, llevándoselo a su «lugar de la Mancha», un desplante o ultraje de este tipo llevaba frecuentemente a peleas de sangre y farragosos pleitos de honor; por ejemplo, en la población de Miguel Esteban (Toledo), inmediata a El Toboso, el adolescente hidalgo local Fernando de Acuña ha sido capaz de derribar el monumento del Santísimo Sacramento y patearlo públicamente en plena celebración de Semana Santa dentro de la iglesia parroquial porque en el reparto y la precedencia de las tres llaves se ha sentido preterido frente al alcalde, el párroco y otras autoridades; el mismo díscolo protagonista cuando en una procesión anterior, no fue puesto en el lugar preeminente, tomó el palo de un estandarte y se lió a palos con la cabecera del desfile, actos todos ellos que le llevaron a ser procesado por la inquisición en 158017.

Para aportar otro ejemplo fuera del Quijote, el corregidor de Murcia veladamente citado en la anagnórisis de la novela ejemplar de La gitanilla (1613), llamado en la ficción Fernando de Acevedo, pero probable trasunto de Fenando de Vera (1595), cuando era un cargo de postín en su Mérida natal unos años antes provocó una verdadera batalla campal dentro de la iglesia parroquial contra el resto de próceres locales por no respetar su asiento (1609) ${ }^{18}$.

\section{LA PRIMERA HISTORIA AÑADIDA Y OMITIDA: EL ÁLAMO DE MEDINA DEL CAMPO EN UN RELATO «TOLEDANO»}

Después Cervantes, como venimos indicando, al igual que realizó en la mayor parte de las Novelas ejemplares, utiliza múltiples y muy diversos materiales, verídicos, pero procedentes cada uno de diferentes origenes históricos para conformar una heterogénea mezcla que hace irreconocible la anécdota inicial principal. Proponemos que el escritor estructura aquí también su narración en diferentes estratos por los que superpone el chascarrillo del duque de Medina Sidonia u otro similar, una serie de personajes que podríamos denominar «principales» que en nada tienen que ver con ella, que por supuesto no la protagonizaron en la realidad - como propuso erróneamente la corriente de los modelos vivos-, y todo ello en un bloque conjunto que a su vez se inserta en un tercer nivel que es el ámbito toledano y manchego que podríamos considerarlo un entorno histórico sobrevenido y espúrio dada la heterogénea procedencia de todos los materiales folklóricos anteriores.

Las descripciones que hace Cervantes de los personajes protagonistas en sus obras a veces son detalladas, por ejemplo en los casos de Filipo de Carrizales (EI celoso extremeño), Antonio de Villaseñor ${ }^{19}$ (el Persiles) o el Ruy Pérez de Viedma (El

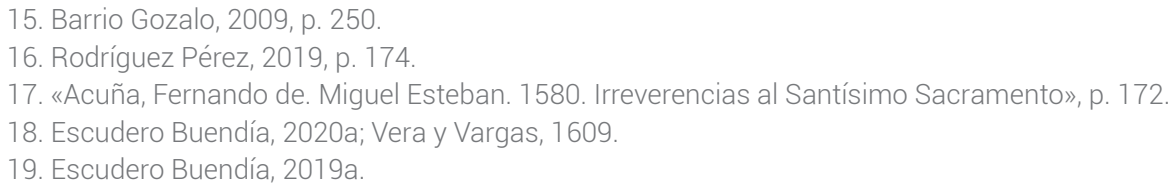


capitán cautivo), a las que podemos considerar verdaderas novelas de aventuras en miniatura, con sus idas y venidas, periplos indianos, peripecias soldadescas, hasta cuentos externos a su vez interpolados unos sobre otros ${ }^{20}$.

Sin embargo en el Álamo de este cuento se nos hurta hasta el nombre propio, y el autor lo despacha en dos trazos gruesos, donde nos dice exclusivamente cómo se llama y su filiación; nos encontramos de nuevo con otra de las historias que podríamos denominar «omitidas» y que nunca acabaremos de comprender del todo porque hemos perdido las claves que el autor dejó para ser subliminalmente sobreentendidas por los lectores de la época, como por poner un ejemplo, sucede también en el episodio de la muerte de Diego de Parraces en el Persiles (1617) ${ }^{21}$ :

- Vive en La Mancha.

-Es un hidalgo de los Álamos de Medina del Campo.

-Está casado don doña Mencía de Quiñones.

Con esta breve semblanza, pensamos que, aunque estamos muy lejos de saber la intención última de Cervantes, sí es posible establecer con cierta certeza a quién pensaría un lector de la época que estaba apuntando esta cita, al menos al grupo de hidalgos a los que se estaba refiriendo, porque son pocos los candidatos en la época convivientes con Cervantes que pudieran acercarse a esta descripción, en concreto pensamos que solo dos:

-Antonio de Álamos y Ruiz de Mayorga, nacido en 1580 en Medina del Campo, Caballero de la Orden de Calatrava, quien se había casado con Constanza de Quiñones: es el candidato idóneo porque todo toledano y vallisoletano lo sabría dado que años después sus descendientes se convertirían en los marqueses de Villasinda y así lo recoge Luis de Salazar y Castro en sus genealogías ${ }^{22}$.

- Su hijo Josef de Álamos, también casado con otra Quiñones, en este caso Antonia, pero había nacido en Toro mucho más tarde y su primer hijo -Francisco Antonio de Álamos y Quiñones-, fue bautizado en León en 1646, por lo que con estos personajes estaríamos fuera del radar cervantino tanto por fecha como por geografía.

Las intenciones de Cervantes: esta idea contradice claramente la expresada por Gregorio Marañón, para quien desde luego el modelo vivo que inspiraría esta mención no es otro que Baltasar de Álamos y Barrientos, «uno de los mejores escritores de su siglo» 23 , y por tanto era una cita a esta familia directa, limpia, sin segundas intenciones y por tanto positiva24.

20. Escudero Buendía, 2019c.

21. Lozano, 1998, pp. 182-184; Baquero Escudero, 2003, p. 189.

22. Salazar y Castro, 1734 , fol. 169.

23. Marañón, 1945, p. 329.

24. Redondo, 2012, p. 119. 
No hay que forzar mucho la imaginación para suponer que Cervantes acudiría a este influyente personaje en cualquiera de los muchos apuros de su vida. Y que, tal vez, la gratitud le hiciera citar a los Álamos, cuando escribió el Quijote, como prototipo de los buenos hidalgos de Castilla ${ }^{25}$.

Pero dado que en otros momentos, como por ejemplo en los Avendaño de La ilustre fregona, a los que el genio de Alcalá intitula nada más empezar como «caballeros de Burgos», cuando eran conversos y se habían hasta mudado el apellido y el solar para no ser reconocidos ${ }^{26}$, podemos dentro del entorno jocoso de las menciones sanchescas permitirnos poner en una razonable duda este aserto de alabanza por varios motivos:

- Lo primero que nos planteamos es que podría estar mencionándolos por un posible pasado converso de estos Álamos, porque existen varios puntos que podrían hacernos dudar de su limpieza de sangre: el concejo y hombres buenos de Medina del Campo ya habían discutido la hidalguía en una fecha tan temprana como 1483 -donde se descubre que los Álamos de Medina del Campo se habían mudado el apellido desde el González de Cuenca original-, y luego lo hicieron más tarde otra vez en $1563^{27}$, además el Juan de Álamos patriarca de todo el clan fue recaudador de la villa ${ }^{28}$, y tenía negocios y casas relacionados con el hospedaje y las mercadurías de las ferias ${ }^{29}$, además de que ya usaba más mulas que caballos como lo hacían sus antepasados ${ }^{30}$, lo que son oficios y situaciones quizás no muy adecuados para aparentar ser caballero e hidalgo.

Pero claro, tanto Gregorio Marañón que los considera intachables — «Don Baltasar no era ni judío, ni protestante, ni agitador de profesión, sino un hidalgo de sangre limpia, cristianísimo, que en los reinados siguientes llegó a ser uno de los más respetables e influyentes varones de la Corte» 37 - como muchos de los testigos de los procesos de hidalguía -familiares y allegados, eso sí-, cuentan como Ferrand González de Cuenca fue a la batalla de Olmedo con sus caballos, volvió con una ropa blanca atravesada con una banda dorada y fue recibido por la mismísima reina Leonor ${ }^{32}$, lo que no garantiza nada, pero sin duda les otorgaba apariencia de tales.

-Era «un grajo y un cuervo» dispuesto a aprovecharse de la carroña de sus amigos. Lo segundo que nos hace dudar, y quizás más probable, es que además de religioso y astrólogo -recordemos al personaje de Grisóstomo en el Quijote (1605), quien también lo era-, Baltasar de Álamos y Barrientos fue íntimo amigo y preceptor de Antonio Pérez, lo que le costó la enemistad del mismísimo rey, y la cárcel con grilletes en Madrid durante años - «Pero por de pronto, su amistad con Pérez, que le engañó como a tantos otros, le costó ir a la cárcel, de la que no

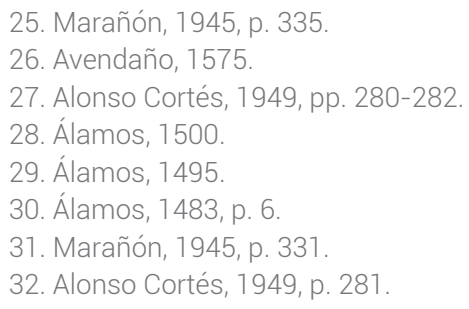


salió hasta la muerte de Felipe II»-, y aunque en principio renegó de esta relación, está claro que fue por conveniencia, porque después dejó los hábitos para intentar casarse con la propia hija de Pérez, exiliado en París, y si no fuera por la oposición de éste hablando con cajas destempladas de su otrora amigo y consejero -era un grajo y un cuervo que quería «picar en aquel cuerpo como si estuviera arrojado a la campaña ya» ${ }^{33}-$, lo hubiera conseguido.

Conclusión: ahora sí, la biografía del más insigne de todos los Álamos de Medina del Campo de fines del dieciséis no tiene desperdicio, y lo pone como objeto de interés literario al mismo nivel que todos los enemigos de Felipe II y de la monarquía hispánica que Cervantes cita con profusión exultante por ejemplo en su novela ejemplar Las dos doncellas -Vique, Cardona, Granolleques-, y por tanto todos estos datos conjuntos podrían ser otra de las que llamamos «historias omitidas» que deberíamos conocer para entender el contexto en que se escribieron. Dejamos para la crítica entender con estos antecedentes si estamos en una burla o una alabanza soterrada porque hasta ese punto la interpretación queda abierta.

El contacto de Cervantes con los Álamos: ¿es este otro relato además con fuentes primarias toledanas? Pero claro, ni Baltasar de Álamos Barrientos, ni por supuesto Antonio de Álamos y Ruiz de Mayorga nunca vivieron en La Mancha o fuera de Valladolid y la Corte, ¿a quién estaba haciendo referencia concreta Cervantes situando a algún miembro del linaje tan lejos de su solar de Medina del Campo? Según nuestra opinión, como realiza también en El celoso extremeño con Filipo de Carrizales o en La ilustre fregona y en sus Novelas ejemplares del ciclo toledano, se está refiriendo a la familia en general nombrando vagamente a alguno de sus miembros más conocidos o desconocidos, y como ya establecieron Francisco Rodríguez Marín (1913) y Luis Astrana Marín (1948-1958), en este caso a quien tenía el autor más cerca era a los Álamos de Esquivias (Toledo), donde residió con su mujer ${ }^{34}$.

Como segunda posibilidad de contacto entre ambos, como veremos al final, una segunda o complementaria opción serían otro grupo de escribanos del entorno de El Toboso y Quintanar de la Orden (Toledo), es decir, que a pesar de que en el episodio se habla de Medina del Campo, que sería el solar de origen de esta familia o de La Herradura (Málaga) donde ocurre ficticiamente el fatal desenlace de uno de ellos, lo cierto es que lo más probable es que estemos ante otro relato cuyas raíces últimas y sentido esté también en el periplo autobiográfico toledano del autor.

Hemos intentado profundizar aun más en ellos, pero los Álamos de Esquivias son muy poco conocidos, y los cervantistas decimonónicos apenas nos dan dos nombres procedentes de escuetas partidas de libros parroquiales o participaciones como testigos en pleitos; un tal Alonso de Álamos que aparece en un proceso por el agua con el pueblo contiguo de Borox ${ }^{35}$, y un Juan Rodríguez del Álamo fallecido en 160436. Poco bagaje para poder hacer una identificación y saber las relaciones de 
parentesco que pudieran tener con la familia política de Cervantes por mucho que el propio Astrana insistiera en la relevancia de estos datos y en la unicidad de este apellido en ese entorno, que no lo era.

\section{LUIS OSORIO DE MARAÑÓN: CABALLERO DE SANTIAGO Y PERSONAJE DE BERBERÍA (¿1516-1563)}

Sancho nos sigue contando que doña Mencía de Quiñones es hija de un tal Alonso de Marañón que murió en La Herradura, el conocido naufragio de la flota española de 1562 en el que murieron miles de soldados; así de nuevo tenemos una mezcolanza y embrollo de menciones, que en nada tienen que ver con la anterior no existieron tales personajes con estas relaciones familiares, como ya habríamos deducido desde el principio-, cuyo juego literario es el fondo jocoso del asunto; viendo la apuesta de Cervantes, podemos entender que en su mundo de ficción:

-Alonso de Marañón era caballero de Santiago.

-Murió en La Herradura en 1562.

- Que estaría casado también con una Quiñones, y que presumimos, porque no se nos aclara, que su hija Mencía debió de tomar el nombre de la madre.

Dada la mezcla de apellidos, lo abundantes que eran en la época, y la falta de medios de búsqueda provocó que la teoría de los modelos vivos se apagara de nuevo sin ofrecer una identificación viable del contexto de este episodio, tampoco en el linaje Marañón: tan solo tenemos de nuevo la propuesta del egregio médico Gregorio Marañón, que siguiendo la línea de su apellido, incursionó también en el cervantismo y en concreto en este episodio (1945).

Según este erudito y siguiendo a Gerardo Moraleja cronista de Medina del Campo y otros que cita, Alonso de Marañón sería un morisco de esta ciudad, contemporáneo de Baltasar de Álamos y Barrientos, quien sería el modelo citado en primer lugar, con tres hijos (1575-1583) y casado con Francisca de la Fuente o Francisca de Cogollos, y por tanto deducimos que el «cuento de los asientos» para este autor estaría situado en Valladolid ${ }^{37}$. Pero claro, identificar al que se describe como cabaIlero, vinculándolo a un morisco, hace presuponer una inquina e ironía a Cervantes mucho máyor de la que pensamos que contiene este cuento.

De hecho, podemos acercanos a las fuentes históricas de esta mención con otros personajes históricos más adecuados tanto por homonimia como por similitudes de oficios y circunstancias; en realidad, sí que existieron en la época dos hermanos y un suegro que, con sus biografías acumuladas, nos dan una descripción más aproximada a este embrollo cervantino:

-El primero, Alonso [Osorio] de Marañón, señor de las villas de Losada y Fresneda, aportaría su nombre y el hecho de que estaba casado nada menos que con Juana de Castro y Quiñones (1565), hija del conocidísimo Cristóbal Vaca de Castro, juez pesquisidor en el virreinato del Perú (1541-1545) y consejero del de Cas-

37. Marañón, 1945, p. 335 
tilla (1556), con lo que añadiríamos un componente indiano inferido a este cóctel, muerto de muerte natural en 1583, según consta de la documentación consultada. -El segundo, un caballero de Santiago que podría encuadrarse mucho mejor con la descripción cervantina, aunque no con el nombre: se trata de Luis Osorio de Marañón, que no murió en La Herradura, pero sí dos años después (1564) de un arcabuzazo en la conquista del Peñón de Vélez de la Gomera, donde también murió Francisco de Mendoza, Capitán General de las galeras de España ${ }^{38}$.

El que el ingenio de Alcalá conocía estos hechos al detalle no cabe duda, ya que les dedica expresamente su obra El gallardo español (1615), con lo que en otro giro de guión aparece de nuevo fugazmente el tema de berbería que tanto influyó en la narrativa cervantina; además, como tercera posibilidad no tenemos que olvidar, que su abuelo, el toledano Pedro de Marañón, regidor y caballerizo real, también era Caballero de Santiago.

El que Cervantes pudiera referirse genéricamente a una familia de hidalgos, mezclando hechos protagonizados vagamente por varios de sus miembros no es algo excepcional en la narrativa cervantina como insistentemente estamos mencionando en este artículo; otros casos cercanos, poco conocidos, podrían ser los Carrizales de El celoso extremeño (1613), los Villaseñor-Ludeña en el Persiles (1617), o Antonio y Juan de Gamboa en La señora Cornelia - cambio de nombres propios-, o se utilizan los correspondientea a miembros poco conocidos del linaje o los de sus antepasados como los Hernando de Cifuentes en La española inglesa ${ }^{39}$ o Diego de Villaseñor en el Persiles ${ }^{40}$.

\section{¿POR QuÉ CERVANTES SE ACUERdA DE LOS MARAÑóN?: OTRO LINAJE DE CABALLEROS TOLEDANOS DE DUDOSA FILIACIÓN Y CON BAGAJE AMOROSO}

Alonso Osorio de Marañón y su hermano proceden de Astorga (León), de hecho eran nietos del marqués de Astorga; a pesar de ser señor de Losada y Fresneda, es decir, un aspirante a alta nobleza, son prácticamente desconocidos en la historiografía de la época: fuera de las genealogías, su único biógrafo y recentísimo es Manuel Arias Martínez (2010), quién es el único pero apenas nos puede aportar datos para entender si fue así, por qué sería un objeto literario cervantino.

En principio sabemos que vivió en Valladolid con su segunda esposa, Mayor Enríquez, desde 1560 hasta que esta falleció en 1562, que antes y después vivió en Astorga (León) con su primera mujer Ana de Sarmiento (†1554), y que lo volvió a hacer con la tercera y última Juana de Castro y Quiñones hasta su muerte (†1583), en unas casas que después de las del marqués, su deudo, eran las más importantes de la ciudad, hasta tal punto que la plazuela donde estaban situadas se llamaba popularmente en el siglo XVII «don Alonso de Marañón» ${ }^{41}$.

38. Escudero Buendía, 2006.

39. Cifuentes, 1587, fol. 10 r.-10 v.

40. Escudero Buendía, 2019b.

41. Arias Martínez, 2010, p. 21. 
Localizado el inventario de los bienes a su fallecimiento, tan solo aparecen una tabla de la Virgen María, un crucifijo, un retrato anónimo de mujer en tabla, y un único libro de la Crónica de España: escasísimo bagaje cultural y bibliófilo para el señor de Cobrana ${ }^{42}$, pero además para lo que nos interesa a nosotros en este momento, un personaje tan insustancial que nos cuesta encontrar algún argumento sin contradecirnos a nosotros mismos para encontrar el por qué, repetimos de nuevo, pudiera ser interesante mencionarlo en un cuento, aunque tan solo fuera incidentalmente. Sin embargo, precisamente esto, que fuera anodino y tan pueril que acabó con su linaje por línea recta, puede darnos la pista de por qué sí que podemos contar con él; es más, el desastre de su familia es tal, que su viuda ingresará en un convento (apéndices), y su herencia y nombre acabará en unos desconocidos parientes italianos ${ }^{43}$.

Un linaje toledano: no podemos olvidar, que tanto él como su hermano Luis -el caballero-, eran hijo de Diego Osorio, comendador de Ocaña y de Catalina de Marañón, toledana, hija del regidor de la ciudad Pedro de Marañón, caballerizo mayor del Rey Católico, casado con Narbona de Ludeña; este último protagonizó múltiples escándalos en la ciudad en el intermedio del medioevo y la modernidad. A nosotros no nos cabe duda de que si el autor pudo oir hablar de ellos, debió ser con toda seguridad en Toledo, pero, ¿por qué eran conocidos estos Marañón y que los hacía estar bajo el punto de mira de plumas afiladas?

En primer lugar, el escándalo de Pedro de Marañón. El profesor Óscar López Gómez ha estudiado en profundidad el conflicto que provocó la insistencia del rey Fernando en influir en la vida local de Toledo incluyendo a su Caballerizo Mayor, primero como Escribano del Crímen (1490), y después como regidor de la ciudad en sustitución de Diego García de Cisneros, que había fallecido; tanta fue la oposición que los regidores estuvieron 20 días sin reunirse para no nombrarle; no sirvió de nada, ni tampoco cuando Marañón solicitó sentarse en el banco junto a los regidores caballeros (1511-1514): a pesar de la oposición de los linajudos Acuñas, CarriIlos, Silvas, Herreras, Guzmanes, Ayalas y Guevaras, la voluntad real se impuso ${ }^{44}$.

¿No le consideraban ni hidalgo, ni caballero al nivel que ellos? Es obvio que si se resistieron a sentarle con los caballeros, sería por algo, lo desconocemos, pero a lo que a nosotros nos interesa en este momento es que estas disputas medievales en los linajes toledanos y las dudas sobre su limpieza de sangre, que corrían de boca en boca oralmente en forma de lo que podríamos llamar cuentos folklóricos o más aún, mitos fundacionales, inventados en muchos casos por estas familias para poder conseguir hábitos, cargos y prebendas y limpiar su pasado - porque esas grandilocuentes fazañas de sus antepasados lo eran ${ }^{45}$-, son campo abonado para el interés literario cervantino, quien sabemos ciertamente que también los refleja por este motivo y como burla de algunos de ellos en su ciclo toledano dentro 
de las Novelas ejemplares (1613) por ejemplo podemos destacar en La ilustre fregona (Carriazo -espúrios-, Avendaño -conversos-) e incluso puede que incluso en el mismo Quijote (1605) (Quijadas, acusados de ambas cosas, conversos e ilegítimos $)^{46}$

En segundo lugar, Diego de Osorio el enamorado. Un segundo punto y aparte por el que sabemos que Cervantes conoció a estos marañones paisanos suyos y que pudo avivar su interés, es porque el padre de Alonso y Luis de Marañón, Diego de Osorio, saltándose las normas de las costumbres de la época, con matrimonios concertados, y de la importancia de su linaje, se casó con Catalina de Marañón; tanto es así que nada menos que Gonzalo Fernández de Oviedo incluyó la anécdota en sus Batallas y Quinquágenas (1550-1552) y le denominó el enamorado:

Porque se casó voluntariamente con una dama que bien le pareçió, de la reyna de Aragón, muger segunda del Cathólico Rey don Fernando, la reyna Germana, y aquesta dama se llamava doña Catalina de Marañón, hija de un caualleriço del rey llamado Marañón, cavallero de la Orden de Santiago. Y como don Diego tuvo agrado de aquella gentil dama, no atendió a otras dotes mayores, que él huviera en Castilla por ser quién era ${ }^{47}$.

\section{¿UNA SEGUNDA VIDA PARA SUS PERSONAJES?: EL POETA PUEDE CONTAR LAS CO- SAS COMO DEBÍAN SER (QUIJOTE, II, 3)}

Un dato trascendental para entender este pasaje y del que nos informa de nuevo el biógrafo de su casa es que los dos hermanos no tuvieron descendencia, y no es porque Alonso Osorio de Marañón no lo hubiera intentado - porque se casó tres veces-, e incluso el 24 de noviembre de 1575 llegó a bautizar a un hijo suyo en la Iglesia de Santa Marta en Astorga (León) llamado Diego Antonio, que podemos entender que no llegó a la madurez ${ }^{48}$.

Dado que en el personaje de ficción se nos dice que tuvo una hija -Mencía de Quiñones-, si lo interpretamos literalmente nos haría descartar cualquier identificación, aun lejana, de estos Osorio Marañón como los destinatarios de la mención cervantina, pero es que esto es también un sello que es muy utilizado por el autor; de hecho, hace que este caballero engrose probablemente la nómina de personajes de frontera, al límite, miembros de linajes muy destacados que sin embargo no tuvieron descendencia y en muchos de los casos llevaron a su apellido a la desaparición o a su familia a pasar graves problemas por su ineptitud.

En todo caso, la pregunta debería ser ésta: ¿por qué tanta precisión histórica para los detalles cuando el eje de la trama, es decir, el niño - fruto de los amores de Alfonso y Comelia- constituye una auténtica tergiversación histórica? El duque de Ferrarra se casó tres veces, pero nunca con una Bentivoglio, y, si tuvo amores, 
no tuvo nunca hijos de estos amores, pues no se le conoce descendencia alguna, ni legítima ni ilegítima. ¿Cómo explicar entonces esta curiosa distorsión de la historia? ${ }^{49}$

Como vemos en este comentario de la profesora Frances Luttikhuizen sobre el distópico argumento de La señora Cornelia, la crítica cervantina ha tenido verdaderas dificultades en entender por qué Cervantes utiliza esta técnica para situar el contexto histórico de muchos de sus textos, cambiando destinos y finales que en absoluto ocurrieron - ¿política ficción?-, y a veces se ha entendido, sobre todo por la decimonónica de los modelos vivos, que estamos ante el genio lego y desmemoriado que lo trabuca todo, así trata este tema Isabel Lozano-Renieblas comentando La española inglesa:

Se basa en la falsa premisa de que Cervantes lo confundió todo: el general que atacó Cádiz pero también los ataques a la ciudad. Esto refleja lo arraigada que está, todavía en la actualidad, la idea del ingenio lego y un tanto desmemoriado que escribía al buen tuntún, tan del gusto de la crítica cervantina decimonónica ${ }^{50}$.

Los casos de La señora Cornelia o La española inglesa estudiados por estas profesoras no son algo aislado, los ejemplos se acumulan; nuestra propuesta en este momento es que este Alonso de Marañón también entraría dentro de esta categoría, por supuesto el más lejano Francisco de Mendoza de El gallardo español, mas donde más nítidamente puede verse la inclusión de personajes fracasados rehabilitados o expuestos por la pluma del escritor es dentro del inescrutable Persiles (1617). En un próximo estudio propondremos que hay nada menos que otros tres personajes históricos reflejados por el autor con las mismas circunstancias personales como pueden ser el duque de Nemurs - más conocido-, el conde Domicio y Juan Bautista Marullo, todos ellos según nuestro criterio mal identificados por la crítica o directamente ignorados ${ }^{51}$; para adelantar algún detalle:

-El conde Domicio (Domicio Caracciolo, conde de Torrella?): el escritor atribuye a este personaje en la ficción tres hijos, cuando su posible paralelo real no los tuvo y murió en Flandes ${ }^{52}$.

- Juan Bautista Marulo, al que identificamos con el último conde de Condojanni, napolitano como en la ficción, también se dice de él: «Y acaso trujo con él a Juan Bautista Marulo, padre de Andrea el enamorado», mientras que el Giovanni Battista Marullo histórico murió también célibe en 1629, y a decir de su descendiente y cronista de la familia fue un hombre mediocre e inepto:

[II Conte Don Giovan Battista e la fine della linea primogenita]. «ll figlio Don Giovanni Battista fu un uomo assai mediocre, e, forse per la sua inettitudine, oppure per fatalità di eventi, vide il crollo della Casa» 53 . 
Conclusión: podemos pensar que Cervantes estaba ironizando continuamente con la dudosa hidalguía de Álamos, Marañones, d'Este, Marulos y Caracholos, y además tomando de familias tan linajudas a aquellos miembros menos destacados o que directamente fueron un desastre para sus casas por no tener descendencia o realizar una gestión de su patrimonio funesta que las llevó a la ruina, simplemente para burlarse de ellos y de su desgracia y que esta ironía fuera compartida por los avezados lectores de su época.

Pero también podemos superar esta visión tan simplista y darnos cuenta de que probablemente en alguno de estos casos su deseo sea el contrario, es decir, cambiar el pasado, el final de la historia, rehabilitándolos y dándoles en la ficción una segunda vida en la que corregir los fallos de la primera.

Según nuestro criterio, Cervantes en ningún caso nos ha engañado, está empleando repetitivamente una manera narrativa, una forma de uso de las fuentes históricas y folklóricas que puso expresamente en boca de su personaje Sansón Carrasco, el bachiller, diciendo lo que él entendía que debía hacer un poeta que es cantar no lo que sucedió y lo que fue, sino lo que pudo y debió ser. ¿Quizás esto es parte de una visión ejemplarizante y de ahí viene el título de su colección de novelas? Porque cambiar las circunstancias y los finales de estas historias reales es para el escritor una forma de mostrar para los lectores y generaciones futuras una actitud frente a los debates de la vida, de cómo seguir un camino recto que nunca se debió torcer, y las consecuencias de no haberlo respetado:

- Así es replicó Sansón-, pero uno es escribir como poeta, y otro como historiador: el poeta puede contar o cantar las cosas, no como fueron, sino como debían ser; y el historiador las ha de escribir, no como debían ser, sino como fueron, sin añadir ni quitar a la verdad cosa alguna (Quijote, II, 3).

\section{LA PENDENCIA DE LOS ÁLAMOS EN LA MANCHA (1587-1597): PUEBLA DE DON FADRIQUE Y EL TOBOSO}

Definitivamente y como colofón del análisis de este breve pero intenso episodio, todo este grupo de personajes - principales, secundarios, historias omitidas, argumentos y cuentos de origen folklórico-, se subsumen a su vez en el entorno del ficticio también lugar de Sancho y don Quijote, donde en teoría ocurrió la anécdota, el chisme real que cuenta el escudero; como sabemos, además de la complejidad de este relato, tenemos otra fugaz historia añadida, la de la pendencia del Álamo de La Mancha, en donde presuntamente participó don Quijote cuando solo era el anónimo hidalgo Alonso Quijano, y donde salió herido Tomasillo «el travieso», el hijo de Barbastro «el Herrero» (Quijote, II, 31), punto que también ha merecido estudio54. 
La búsqueda de los antecedentes folklóricos o históricos de una posible pelea vecinal, un episodio de violencia local ${ }^{55}$ en que estuvieran implicados unos hipotéticos Álamos manchegos parece algo inalcanzable y más inverosímil que toda la retahíla de detalles sanchescos; como ya dijimos, los miembros de esta familia en Esquivias - La Sagra (Toledo) son tan desconocidos y sus detalles biográficos tan nimios, que nada podemos esperar, pero en La Mancha toledana por suerte la situación no es la misma.

Porque además de los conocidos en Esquivias, también existen Álamos en el entorno de El Toboso, en principio los más destacados parecen ser los de Puebla de don Fadrique (Toledo) ${ }^{56}$, donde eran los escribanos de la población (1569) y llegaron a ser alcaldes ordinarios de la misma a finales del siglo XVI57; desde allí arribaron al cercano y cervantino El Quintanar, capital de la Gobernación (1577) ${ }^{58}$, y al año siguiente es el escribano en un proceso donde precisamente es herido el herrero de esta población, como el Tomasillo de la ficción, perdiendo algunos dedos la pelea ${ }^{59}$. A partir de 1586 es escribano de número de El Toboso y los protocolos signados por él se cuentan por centenares. Desconocemos si proceden de Medina del Campo, en los procesos desde luego no hacen gala de ello.

Pues bien, este Francisco del Álamo, escribano de El Toboso y alcalde intermitente de Puebla de don Fadrique, se vio inmiscuido no en una única pendencia, sino en varias consecutivas y muy graves que le pudieron costar la vida.

Todo comenzó en el año 1587, cuando lo que en teoría era un escribano más al uso, se convirtió en un elemento de poder local, con tal descaro que podía junto a sus secuaces tenía la impunidad suficiente como para descolgar la campana de una ermita local, trasladarla a la plaza local delante de todos, colgarla de un arco de piedra a la vista de los vecinos, con un libelo difamatorio de la autoridad y no ser denunciado por ello:

Qu'él y otros sus amigos y consortes habían sacado de una ermita una campana y colgándola de un arco de una puerta en la plaza pública de esta villa y en ella pegado un papel escrito en él un libelo infamatorio contra el consejo, justicia e regimiento de la dicha villa 60 .

El libelo era tan desafiante, que no solo se atrevía a calumniar a los alcaldes y regidores locales, sino que iban en contra del propio Licenciado Núñez de Cháves, gobernador en la capital, Quintanar de la Orden: 
Que por ser el dicho Álamo de las calidades de las dichas, persuadió el año de ochenta y ocho a un Gonzalo García, amigo suyo, le pusiese unos capítulos licenciado Núñez de Chaves, gobernador que fue de la villa de El Quintanar ante el doctor Jara que le tomaba residencia, al cual asimismo no llamaban de otro nombre que no «el viejo coleridugo» y por ser los dichos capítulos tan feos y puestos de malicia, sabe este testigo que fue condenado el dicho Gonzalo García en mucha cantidad de maravedíes para la cámara de Su Majestad, y declarado por calunioso acusador como parescerá por la sentencia ${ }^{61}$.

La creación por parte de Francisco del Álamo de estos grupos de presión, por el que llegaron a llamarle «facineroso» obtuvo pronto sus frutos ${ }^{62}$, primero para obtener una regiduría en Puebla de don Fadrique, y más tarde (1593) la ansiada alcaldía, pero claro, el sistema que se utiliza en la Orden de Santiago incluye una insulación mediante unas bolas y sorteo, con unas rígidas condiciones para participar, y al ser regidor Francisco del Álamo no las cumplía, y aún así el Alcalde Mayor le permitió participar como así denuncia el procurador Joan Moyano63.

La pendencia: una turba apresa al alcalde Álamo y lo apalea (1593). Las evidentes irregularidades, sumado a que siendo alcalde el Álamo había encausado a varios de los principales vecinos de la localidad acusándoles de tener deudas con el pósito municipal, y estos a su vez habían huido, refugiándose en sagrado - dentro de la iglesia parroquial-, provocó que en cuanto consiguieron revocarle la vara de alcalde, una turba incontrolada dirigida por el que a la postre sería el nuevo alcalde, Alonso Gallego de Villaseñor, liberó a los apresados, y en masa fueron con la provisión en mano a la casa del Alcalde donde este, su hermana con un puñal y un criado con una espada medio desenvainada les estaban esperando. Poco pudieron hacer, era toda una población en masa, armadas incluso con una vara de carro, y les dieron de palos y les pusieron los grilletes, y estuvo a punto de haber muertes:

Siendo el dicho Francisco del Álamo alcalde como dicho es en la dicha viIla le dijeron muchas e muy feas palabras llamándole de judío y otras afrentas e no contentos con esto el dicho Alonso Gallego [de Villaseñor] que a la sazón era alcalde e compañero del dicho Francisco del Álamo sacó de la iglesia donde estaban retraídos a los dichos Francisco Mínguez e Juan Moreno Baptista, tercero, que como dicho es estaban retraídos por el trigo del dicho pósito e todos juntos y con ellos el dicho Bartolomé Hernández Zurdo y otros fueron a la casa del dicho Francisco del Álamo y estando descuidado llegaron con mano armada y de hecho y con gran violencia le dieron muchos mojicones y palos y echaron otros muchos malos tratamientos e llevándolo a la cárcel por los cabezones e le pusieron grillos y cadena sobre que el dicho Francisco del Álamo se querelló en la Real Chancillería de Granada64.

61. «Francisco del Álamo, de la villa de don Fadrique, contra Alonso Gallego sobre haber quitado la vara de alcalde al interesado», fol. 55r-55v.

62. Escudero Buendía, 2020b, p. 958.

63. «Francisco del Álamo, de la villa de don Fadrique, contra Alonso Gallego sobre haber quitado la vara de alcalde al interesado», fol. 5 r.

64. «Francisco del Álamo, de la villa de don Fadrique, contra Alonso Gallego sobre haber quitado la vara de alcalde al interesado», fol. $11 \mathrm{v}$. 
Con todo lo sucedido, aun así Francisco del Álamo se levantó y consiguió recuperar parte de lo perdido, con lo que la frustración fue haciendo mella en sus enemigos, todos aquellos a los que había encarcelado previamente: al no tener otra opción, le esperaron en la salida hacia Villacañas (el famoso Camino de Toledo a Murcia citado en el Quijote $(I, 4)$ en el episodio de los mercaderes de la seda) cuatro años después (1597), le apalearon con saña en la cabeza y le dejaron tirado en el suelo, prácticamente muerto, con secuelas, sangrando del oído y con la pérdida de trescientos ducados anuales por el arrendamiento de su escribanía, que no podía él llevar personalmente, y que el nuevo alcalde tampoco le permitió arrendar:

Item si saben que poniendo en ejecución lo que dicho él un día que se contaron veinte y seis de abril de este año, llegaron todos los de suso contenidos a do iba el dicho Francisco del Álamo por su camino y le dieron muchos palos y cancharazos e le hicieron otros e muchos malos tratamientos de tal manera que lo dejaron por muerto y llegó a lo último hasta ser ollado y de los dichos malos tratamientos ha quedado y queda muy falto de salud y lleno de enfermedad del sordo65.

Conclusión: este cuarto y último elemento de análisis del corto pero abigarrado episodio de Sancho Panza reconocemos que es el más interesante, pero a su vez el más complicado de imbricar en la verosimilitud y fuentes del relato; la participación en él de un alcalde miembro de la familia Villaseñor, linaje que cita expresamente Cervantes en el Persiles es un punto muy positivo a favor para considerar que pudo ser conocido por el autor.

Pero en ningún modo pudo estar presente en estos episodios, por lo que la existencia de un informante por el que fluyera la descripción de todos estos cuentos folklóricos manchegos se hace apremiante e incluso existiendo este se haría complicado demostrar el conocimiento de un hecho concreto y determinado.

El reciente descubrimiento de un hidalgo del Quintanar de la Orden residiendo junto a Miguel de Cervantes en Esquivias (Toledo) entre los años 1594 y 1607, siendo cuñado de Pedro de Villaseñor y además sobrino de un Antonio de Villaseñor, hijo de militares, con contactos comerciales directos con los herederos del propio manco de Lepanto, los Quijada y los Salazar puede ser la pieza que cierra el círculo y que estábamos buscando para poder completar la procedencia de las fuentes históricas utilizadas por Cervantes ${ }^{66}$.

65. «Francisco del Álamo, de El Toboso, contra Bartolomé Hernández, de la Villa de don Fadrique, sobre agresión y heridas», fols. 13v-14r. 66. Escudero Buendía, en prensa. 


\section{APÉNDICES DOCUMENTALES}

\section{Apéndice núm. 1: personaje histórico de Juan de Álamos}

[Ejecutoria de hidalguía a favor de Juan de Álamos, vecino de Medina del Campo], Valladolid), 1483/08/16. Testigo Diego García González, hijo de Diego García, ome fijodalgo. ACHVA. Pergaminos. Caja 72, doc. núm. 12 [Extracto], p. 6.

Otrosí dixo que conosciera bien al dicho Diego Gonçales, padre del dicho Ferrand González de Cuenca, e abuelo del dicho Juan de Álamos.

E dixo que podía auer los dichos çinquenta e çinco años poco más o menos que lo conosciera, e dixo que lo conosçiera uiuiendo e morando asímesmo en la dicha villa de Medina del Campo, estando en ella casado e tenyendo su casa, e asiento e muger e fijos e fasienda, e asiento por espaçio de diez años e más tienpo, fasta que fallesçiera, e que podía auer estonçe que fallesçiera fasta quarenta e çinco años poco más o menos que lo conosçiera.

E dixo que lo conosçiera porque este testigo hera estonces de hedad de setenta años poco más o menos, e nasçiera e se criara en la villa de Belmonte que está en la Mancha de Aragón; e quando este testigo fuera de hedad de quinze años, se venyera a veuyr e morar a la dicha villa de Medina del Campo, con la Señora Rreyna doña Leonor, nuestra abuela, e porque después este testigo se casara en al villa de Tordesillas, e se venyera a beuyr e morar con su muger a la dicha villa de Medina del Campo, donde fasta estonçes auya veuydo e morado siempre, e porque fabvlara e conuersara muchas vezes con el dicho Diego Gonçalez, abuelo del dicho Juan de Álamos.

Otrosy dixo que savía quel dicho Juan de Álamos que lo presentara por testigo, que hera onbre fijodalgo de padre, e de abuelo; e dixo que lo sabía porque en el dicho tiempo que este testigo conosçiera biuyendo e morando en la dicha villa de Medina del Canpo a los dichos Diego Gonçález e Ferrand Gonçales de Cuenca, abuelo e padre del dicho Juan de Álamos, fasta que fallesçiera e después dellos al dicho Juan de Álamos e sienpre viera que fuera e auya seydo auydos e tenidos e conosçidos e nombrados cada uno de ellos en su tiempo por omes fijosdalgo, biuyendo limpiamente en ábito de omes fijosdalgo, e tenyendo e mantenyendo el dicho Diego Gonçalez escuderos en su casa, e el dicho Ferrand Gonçalez, su fijo, manteniendo cauallos, e armas, e el dicho Juan de Álamos tenyendo algunas veses cauallo e otras veses mulas, llamándose siempre cada uno de ellos en su tiempo omes fijosdalgo.

Otrosí dixo que en este tiempo que este testigo conosciera e ouyera conosçiedo viuyendo a morando en la dicha villa de Medina del Campo al dicho Juan de Álamos e a los dichos sus padre e abuelo, e asta que fallesçieran que siempre viera que auya visto que ellos e cada uno dellos en su tiempo estouyeran e auyan estado en posesión de omes fijosdalgo, de no pechar, ny pagar en pedido, ni en monedas, ny en otros pechos, ni tributos. 


\section{Apéndice núm. 2: personaje histórico Alonso Osorio de Marañón}

[Ejecutoria del pleito litigado por el Monasterio de Santa Catalina de Siena, Orden de Santo Domingo, de Valladolid, como cesionario de Juana de Castro y Quiñones, monja profesa en él, y otros acreedores a los bienes de Alonso Osorio Marañón, su marido, con Juan Osorio Marañón y Luis Osorio, su hijo, sucesores en el mayorazgo de dicho difunto, sobre ejecución de los bienes de Juan Osorio Marañón para restituir la dote a Juana de Castro y Quiñones y pagar otras deudas contraídas durante su matrimonio], 1594-05-18, ACHVA, Registro de Ejecutorias, Caja 1760, 5, p. 2.

Conocida sea a todos los que la presente bieren como yo don Alonso Osorio, señor de las villas de Losada e Fresneda, etcétera: Digo que al tiempo que con la Gracia y Bendición de Dios Nuestro Señor se concertó casamiento entre mi y doña Juana de Castro e Quiñones, mi muger, hija legítima de los llustres Señores Cristóbal Baca de Castro del Consejo Real de Su Magestad, Comendador de las Encomiendas de Palomas de la Horden e Caballería de Señor Santiago, e de mi Señora doña María de Quiñones, su muger, que esté en Gloria, el dicho Señor Baca de Castro e yo otorgamos una escritura de capitulación matrimonial ante el presente escriuano a çinco de março del año pasado de mill y quinientos e sesenta y çinco.

\section{BiBLIOGRAFÍA}

Alonso Cortés, Narciso, «Acervo biográfico», Boletín de la Real Academia Española, tomo XXIX, cuaderno CXXIX, 1949, pp. 279-305.

Arias Martínez, Manuel, Otros Osorio: linaje, casa y ornato. Estudios sobre pequeña nobleza en Astorga, Astorga, Centro de Estudios Astorganos «Marcelo Macías», 2010.

Astrana Marín, Luis, Vida ejemplar y heroica de Miguel de Cervantes Saavedra con mil documentos hasta ahora inéditos y numerosas ilustraciones y grabados de época, Madrid, Editorial Reus, 1948-1958.

Baquero Escudero, Ana Luisa, «Tres historias intercaladas y tres puntos de vista distintos en el primer Quijote», en Actas del II Coloquio Internacional de la Asociación de Cervantistas, Barcelona, Anthropos, 1991, pp. 417-424.

Baquero Escudero, Ana Luisa, «Las historias omitidas en el Persiles», Monteagudo, 3. ${ }^{\mathrm{a}}$ época, 8, 2003, pp. 183-192.

Baquero Escudero, Ana Luisa, La intercalación de historias en la narrativa de Cervantes, Editorial Academia del Hispanismo, Vigo, 2013.

Barrio Gozalo, Maximiliano, «La embajada de España ante la Corte de Roma en el siglo XVII: ceremonial y práctica del buen gobierno», Studia Historica. Historia Moderna, 31, 2009, pp. 237-273. 
Bradbury, Jonathan David, «The Unstated Sources of Cristobal Suárez de Figueroa's Varias noticias importantes a la humana comunicación (1621)», The Modern Language Review, 111.3, 2016, pp. 703-726.

Cervantes Saavedra, Miguel de, El ingenioso hidalgo don Quijote de la Mancha, ed. Francisco Rodríguez Marín, Madrid, Ediciones de la Lectura, 1913.

Daguerre, Blandine, «Para una nueva lectura de los relatos interpolados en la obra de Suárez de Figueroa», en «Melior auro». Actas del IX Congreso Internacional Jóvenes Investigadores del Siglo de Oro (JISO 2019), ed. Carlos Mata Induráin y Miren Usunáriz Iribertegui, Pamplona, Servicio de Publicaciones de la Universidad de Navarra, 2020, pp. 73-86.

Da Costa Vieira, María Augusta, «Sancho Panza: ética y conveniencia aristocrática», eHumanista/Cervantes, 4, 2015, pp. 387-393.

Diego, Sabino de, «Los vecinos de Borox y Esquivias enfrentados por el agua de sus fuentes (1594)», Sociedad Cervantina de Esquivias (Toledo), 2020 [en línea].

Díaz-Mas, Paloma, «Más sobre el cuento de nunca acabar (Quijote, I, 20)», en Dejar hablar a los textos. Homenaje a Francisco Márquez Villanueva, Sevilla, Universidad de Sevilla, 2005, pp. 1031-1062.

Escudero Buendía, Francisco Javier, Francisco de Mendoza «El Indio» (1524-1563), Guadalajara, AACHE, 2006.

Escudero Buendía, Francisco Javier, «El personaje de Antonio de Villaseñor, llamado "El bárbaro". La presencia del referente histórico del Persiles al Quijote», Hipogrifo. Revista de literatura y cultura del Siglo de Oro, 7.1, 2019a, pp. 99-109.

Escudero Buendía, Francisco Javier, «"Son el linaje más antiguo del maestrazgo": los Villaseñor del Persiles desde el punto de vista de sus coetáneos y la documentación de archivo», en «Los trabajos de Cervantes». XIII Coloquio Internacional de la Asociación de Cervantistas, ed. Rafael González Cañal, Cuenca, Universidad de Castilla-La Mancha, 2019b, pp. 115-122.

Escudero Buendía, Francisco Javier, «Dos condes, varios banqueros y muchos mercaderes: personajes históricos italianos en el Quijote, las Novelas ejemplares y el Persiles», comunicación presentada en «Admiración del mundo». XIV Coloquio Internacional de la Asociación de Cervantistas, Venezia, Università Ca' Foscari, 2-4 de octubre de 2019c [inédita].

Escudero Buendía, Francisco Javier, «Fuentes históricas de La gitanilla: el escándalo del secuestro de Teresa de Figueroa, hija del Corregidor de Murcia (1595)», comunicación presentada en el XII Congreso Asociación Internacional Siglo de Oro (AISO), Neuchâtel Universidad de Neuchâtel, 2-6 de noviembre de 2020a [inédita]. 
Escudero Buendía, Francisco Javier, Prosopografía de personajes reales cervantinos en La Mancha (1578-1591). Un reflejo de la sociedad rural en El Toboso del siglo XVI, Tesis Doctoral dirigida por Francisco Crosas López, Toledo, Universidad de Castilla-La Mancha, 2020b.

Escudero Buendía, Francisco Javier, Las otras vidas de don Quijote. ¿Fue el ingenioso hidalgo de La Mancha una persona real?, Barcelona, Ediciones B, 2022 [en prensa].

García López, Jorge, «Finales de novela en las Ejemplares», Anales Cervantinos, XXXV, 1999, pp. 185-192.

López Gómez, Óscar, Violencia urbana y paz regia. El fin de la época medieval en Toledo (1465-1522), Tesis Doctoral dirigida por Ricardo Izquierdo Benito, Toledo, Universidad de Castilla-La Mancha, 2006 [inédita].

López-Salazar Pérez, Jerónimo, «Hidalgos de carne y hueso en la Mancha Cervantina», Pedralbes, 25, 2005, pp. 51-102.

Lozano-Renieblas, Isabel, Cervantes y el mundo del «Persiles», Alcalá de Henares, Centro de Estudios Cervantinos, 1998.

Lozano-Renieblas, Isabel, «Pesquisa sobre el conde de Leste», Hesperia. Anuario de filología hispánica, XVI.2, 2013, pp. 43-57.

Lozano-Renieblas, Cervantes y los retos del «Persiles», Salamanca, SEMYR, 2014.

Luttikuizen, Frances, «Verdad histórica y verdad poética en La señora Cornelia», en Actas del I Coloquio Internacional de la Asociación de Cervantistas, Alcalá de Henares (Madrid), Anthropos, 1990, pp. 265-269.

Luttikhuizen, Frances, "Cervantes y "el Transilvano"», en Peregrinamente peregrinos. Actas del V Congreso Internacional de la Asociación de Cervantistas, ed. Alicia Villar Lecumberri, Lisboa, Fundaçao Calouste Gubelkian / Asociación de Cervantistas, 2004, vol. 2, pp. 1543-1558.

Marañón, Gregorio, «Sobre un hidalgo de la Mancha», Boletín de la Real Academia de la Historia, tomo 116, cuaderno II, abril-junio de 1945, pp. 325-336.

Martín Morán, José Manuel, «La reificación de la palabra en don Quijote», Cervantes. Bulletin of the Cervantes Society of America, 19.2, 1999, pp. 24-36.

Marullo di Condojanni, Carlo, La famiglia Marullo di Messina e le sue vicende (Memorie e documenti), Mesina, Societá Tipografica Editrice Messinese, 1956.

Mendoza Mendoza, Antonio, El regocijo de las musas, Guadalajara, AACHE, 2016.

Ramírez de las Casas Deza, Luis María, Colección de autos generales y particulares de fe celebrados por el Tribunal de la Inquisición de Córdoba anotados y dados a la luz por el Licenciado Gaspar Matute y Luquin, Córdoba, Imprenta de Santaló, Canalejas y Compañía, 1836. 
Redondo, Agustín, «El episodio del libro Flor de los aforismos peregrinos en el Persiles (IV, L): tradiciones culturales, contexto histórico y carácter lúdico», Nueva Revista de Filología Hispánica, LX.1, 2012, pp. 115-132.

Riley, Edward C., Teoría de la novela en Cervantes, 3. ${ }^{a}$ ed., Madrid, Taurus, 1989.

Rodríguez Pérez, Juan Carlos, Las embajadas italianas del marqués de Villagarcía: correspondencia y noticias durante el periodo genovés (1672-1677), Tesis Doctoral dirigida por Fernando J. Bouza Álvarez, Madrid, Universidad Complutense de Madrid, 2019 [inédita].

Santolaria Solano, Cristina, «Alusiones a personajes, pueblos, etc. referentes al Altoaragón», Argensola. Revista de Ciencias Sociales del Instituto de Estudios Altoaragoneses, 88, 1979, pp. 469-488.

Suárez de Figueroa, Cristóbal, El Pasajero, ed. Francisco Rodríguez Marín, Madrid, Renacimiento, 1913.

Suárez de Figueroa, Cristóbal, El Pasajero, ed. María Isabel López Bascuñana, Barcelona, Promociones y Publicaciones Universitarias (PPU), 1988, 2 vols.

Suárez de Figueroa, Cristóbal, El pasajero. Advertencias utilísimas a la vida humana [1617], ed. Enrique Suárez Figaredo, Lemir, Textos, 2018, pp. 355-648.

Suárez de Figueroa, Cristóbal, El pasajero. Advertencias utilísimas a la vida humana, ed. Jonathan Bradbury, París, Université de la Sorbonne, LABEX OBVIL, 2016.

Velasco, Jesús R., «A Sixteenth Century Trial and the Writing of Don Quijote», Blogs, Columbia University, LAIC, Department of Latin American and Iberian Cultures 07/12/2014 [en línea].

\section{ABREVIATURAS DE ARCHIVOS}

AHN (Archivo Histórico Nacional), OOMM (Sección de Órdenes Militares dentro del AHN), AGS (Archivo General de Simancas), ACHGR (Archivo de la Real Chancillería de Granada), AHT (Archivo Histórico de Toledo, sección AHN), ADC (Archivo Diocesano de Cuenca), RAH (Real Academia de la Historia), RGS (Registro General del Sello).

\section{FUENTES DOCUMENTALES}

«A petición de Juan de Álamos, vecino de esa villa, que tenía unas casas en la plaza, en la acera donde se aposenta la mercería, el cual, evocando tales ordenanzas, dice que los armeros se aposentaban desde el cantón de la calle de Ávila hasta donde alcanzaren, y los merceros a continuación, quedando a veces las casas de dicho Álamos sitas cerca del referido cantón, sin huéspedes, no obstante dárseles a las que estaban a sus espaldas», AGS, RGS, Leg. 149509, núm. 34. Digitalizado en el PORTAL PARES del Ministerio de Cultura: PARES | Archivos Españoles (mcu.es) 
[«Acuña, Fernando de. Miguel Esteban. 1580. Irreverencias al Santísimo Sacramento»], Suspenso, ADC, Legajo 307, 4453.

[Al corregidor o juez de residencia de Medina del Campo, para que cumpla las ordenanzas que esta villa tiene referentes al aposentamiento de sus ferias], Burgos, 1495/09/24. AGS, RGS, Leg. 149509, núm. 34. Digitalizado en el PORTAL PARES del Ministerio de Cultura: PARES | Archivos Españoles (mcu.es).

[Andrés de Carrión, hidalgo de Miguel Esteban, contra Pedro de Encinas, de Quintanar de la Orden y exalguacil de Cartagena, por espaldarazos en el juego de pelota], 1578, AHN, OOMM, AHT, Leg. 12003.

[Cifuentes, Francisco de. Real provisión ejecutoria de hidalguía], 1587-07-23, ACHGR, Caja 4568-004.

[Cumplimiento de los libramientos dados por Juan de Álamos, recaudador, vecino de Medina del Campo, a favor de Francisco Bravo], Valladolid, 1500-08-30, AGS, RGS, Leg. 150008, núm. 129.

[Ejecutoria de hidalguía a favor de Juan de Álamos, vecino de Medina del Campo (Valladolid)], ACHVAl Pergaminos, Caja 72, doc. núm. 12.

[Ejecutoria del pleito litigado por el monasterio de Santa Catalina de Siena], Valladolid, 1594-05-18, ACHVA, Registro de Ejecutorias, Caja 1760, Exp. 5.

[El fiscal de El Toboso contra Pedro Martínez, mozo y criado, sobre acusación por hurto de un asno, propiedad de Catalina de Salanteffi], 1577, AHN, OOMM, AHT, Leg. 11843.

[Fernando de Vera y Vargas y su hijo Fernando de Acevedo, sobre el lugar que ocupa en la iglesia, asientos en fiestas], Mérida, 1609, AHN, OOMM, AHT, Leg. 13790.

[«Francisco del Álamo, de la villa de don Fadrique, contra Alonso Gallego sobre haber quitado la vara de alcalde al interesado»], 1593, AHN, OOMM, AHT, Leg. 18234.

[«Francisco del Álamo, de El Toboso, contra Bartolomé Hernández, de la Villa de don Fadrique, sobre agresión y heridas»], 1597, AHN, OOMM, AHT, Leg. 18237.

[Pleito del fiscal del rey y el concejo de Carrión de los Condes (Palencia) con Juan de Avendaño y su hijo Juan Alonso de Avendaño, vecinos de Carrión de los Condes (Palencia) y Jerónimo Alonso de Avendaño, su primo, vecino de Villadiego (Burgos), sobre falsificación de pruebas documentales y soborno de testigos en el pleito de hidalguía de Juan de Avendaño], Valladolid, 1575. ACHVA, Sala de hijosdalgo, Caja 1996, Exp. 3.

[Pruebas para la concesión del título de caballero de la Orden de Alcántara de Domicio Caracciolo y Carrafa Archela y Carrafa, natural de Nápoles], 1592, AHN, OOMM, Caballeros de Alcántara, Exp. 262.

Salazar y Castro, Luis, -1734- [Costados de José Antonio Álamos y de la Serna, Quiñones y Vozmediano, II marqués de Villasinda], RAH, Signatura 9/295, fol. 169. 